\title{
DERMATOGLYPHIC APPRAISAL OF MULTIPLE BIRTHS WOMEN IN IGBO-ORA AND OGBOMOSHO, SOUTH WEST, NIGERIA
}

\author{
Kehinde T. Adenowo ${ }^{1}$, Olugbenga O. Eweoya ${ }^{2}$, Olugbemi T. Olaniyan ${ }^{3}$, Abayomi Ajayi ${ }^{4}$
}

\author{
${ }^{1}$ Anatomy Department, Olabisi Onabanjo University, Sagamu, Ogun State, Nigeria \\ ${ }^{2}$ School of Medicine and Allied Health Sciences, University of the Gambia, The Gambia \\ ${ }^{3}$ Laboratory for Reproductive Biology and Developmental Programming, Department of Physiology, Edo \\ University Iyamho, Edo State, Nigeria. \\ ${ }^{4}$ Anatomy Department, Kogi State University, Anyigba, Kogi State, Nigeria. \\ *All correspondence: Eweoya, 0.0, +2203831107, email: eolawale@utg.edu.gm
}

\begin{abstract}
The scientific study of epidermal ridges on the palms and toes is termed dermatoglyphics. Multiple births occur when more than one fetus results from a single pregnancy. This study is aimed at determining the relationship if any between multiple births and palmar flexion creases. Two hundred Igbo-Ora and one hundred Ogbomosho healthy and consenting adult female indigenes aged between 25-50 years were recruited and grouped into 4; group I consisted of multiple births women in IgboOra; group II consisted of single births women in Igbo-Ora; group III consisted of multiple births women in Ogbomosho; and group IV consisted of single births women in Ogbomosho. A total of 600 palms (Igbo-Ora $n=400$; Ogbomosho $n=200$ ) comprising of both hands were used in the study. Palm prints samples were obtained by asking the participants to wash their hands, towel dry them, after which they were stained with stamp ink pad and prints made on A4 paper in duplicates. Palm print patterns of 105 (Igbo-Ora) and 50 (Ogbomosho) women with multiple births were compared with 95 (Igbo-Ora) and 50 (Ogbomosho) women with single births. The percentage number of primary, $\mathrm{P}$ and intersection, I of palmar creases with complete transverse creases, C (PIC) 300 bilaterally was significantly greater $(p<0.005)$ in the hands of Igbo-Ora multiple births women $(52.4 \%)$ than their single births women (37.4\%) while same trend was observed for Ogbomosho women although difference was statistically insignificant, $(p>0.005)$. In both Igbo-Ora and Ogbomosho women, PIC 310 bilaterally was found to be significantly higher $(p<0.05)$ in both hands of single births women than the multiple births women. Hence, dermatoglyphics can be said to have relationship with a woman's tendency to giving birth to multiples.

Keywords: Multiple births, dermatoglyphics, palmar flexion creases, Ogbomosho, Igbo-Ora
\end{abstract}

\section{INTRODUCTION}

Multiple births occur when more than one fetus results from a single pregnancy (Akinboro et al., 2008). Different names are used for multiple births depending on the number of offspring, common multiples are two and three and are known as twins and triplets although this term is most applicable to placenta species (Kulkami et al., 2013). However, multiple births can be monozygotic or dizygotic in nature (Lazarov et al., 2016). Monozygotic twin is, if the twin results from splitting of a single fertilized egg into two or more identical embryos while dizygotic twins result from fertilization of more than one egg (Eboh and Arko-Boham, 2008). Twins are revered in some societies while they are seen as normal individuals in other societies (Smits and Monden, 2011) and some communities in Nigeria regarded twins as evil and were being killed until $19^{\text {th }}$ century when the practise was stopped by a Scottish missionary, Mary Slessor, (Achebe, 1994; Bastian, 2001). 
Scientific study of patterns of lines and ridges on the fingers, hands, toes and soles of the feet is termed 'dermatoglyphics' (Oladipo et al., 2012; Offei et al., 2014). The characteristic pattern of epidermal ridges develops in mammals during fetal life and remains unchanged throughout life (Ravindranath and Thomas, 1995; Dehankar, 2012). Palm prints reveal more information than fingerprints (Ghosh et al., 2016). The PIC model given by Wu et al., 2004 was used for palmar identification and this takes into consideration the number of primary palmar creases $(P)$, intersection of primary palmar creases (I) and complete transverse flexion creases (C). Various dermatoglyphic parameters like Total Frictional Ridge Count, Atd angles, 2D:4D digital ratio, fingerprint patterns and palmar flexion creases among other parameters have been studied but for the purpose of this paper, the relationship between multiple births and palmar flexion creases were studied. Multiple births have been studied extensively with other parameters, but little is known about the study of epidermal ridges in the hand and its predictive value for multiple births in women despite its simplicity, inexpensive and non-invasive nature. Therefore, this study is aimed at determining the relationship, if any, between multiple births and palmar flexion creases. High surviving twinning rate in Igbo-Ora (Mosuro, 1996; Smits and Monden, 2011), which ranked highest in Nigeria and the World, made us to study why there is a high twinning rate in the town.

\section{METHODOLOGY}

The study design used was a cross sectional case control conducted on volunteers from Igbo-Ora and Ogbomosho in Oyo State, Nigeria. Ethical approval was obtained from Ladoke Akintola University of Technology Teaching Hospital Ogbomosho and informed consent statement was explained to the illiterate subjects for thumb printing while consent forms were duly signed by the literate subjects. The study was carried out for a period of six months (February to August 2016). Healthy and consenting adult female subjects recruited included two hundred (200) indigenes from Igbo-Ora and one hundred (100) indigenes from Ogbomosho aged between 2550 years. The subjects were grouped into four (I - IV); group I consisted of women who had given birth to twins in Igbo-Ora; group II consisted of women who had never given birth to twins in Igbo-Ora; group III consisted of women who had given birth to twins in Ogbomosho; group IV consisted of women who had never given birth to twins in Ogbomosho.

The sample size of the participants was calculated by Yamane equation at 95\% confidence level, and 399 subjects were needed, their bio-data obtained using a structured questionnaire to which they supplied answers. Dermatoglyphics prints were taken by the 'Ink Method' described by Cummins and Mildo (1961). Subjects were asked to wash their hands, towel dry them, after which they were dabbed with stamp ink pad and prints made on A4 paper, the palm prints were taken in duplicates from all the participants. A total of 400 and 200 respective palms of Igbo-Ora and Ogbomosho subjects comprising both hands were subjected to dermatoglyphic analysis using magnifying hand lens. The samples were analysed grossly for the number of primary palmar flexion creases $P$, intersection, $I$, of primary palmar flexion creases and complete transverse flexion creases, C. Dermatoglyphic patterns of 105 (Igbo-Ora) and 50 (Ogbomosho) women with multiple births were compared with 95 (Igbo-Ora) and 50 (Ogbomosho) women with single births.

All subjects were indigenes of Igbo-Ora and Ogbomosho and have been living there since birth. Subjects with any form of anatomical hand deformity were excluded from this study. The palmar flexion creases were studied for each hand and analysed, compared, evaluated and verified. Data entry and analysis were done 
using SPSS version 23.0 computer software package. Descriptive statistical analysis was applied and $\mathrm{p}<0.005$ was considered as significant.
Yamane formula for sample size: $\mathrm{n}=\mathrm{N} / 1$ $+\mathrm{Ne}^{2}$ (Yamane, 1967). Confidence level of $95 \%$, error margin of $5 \%$.

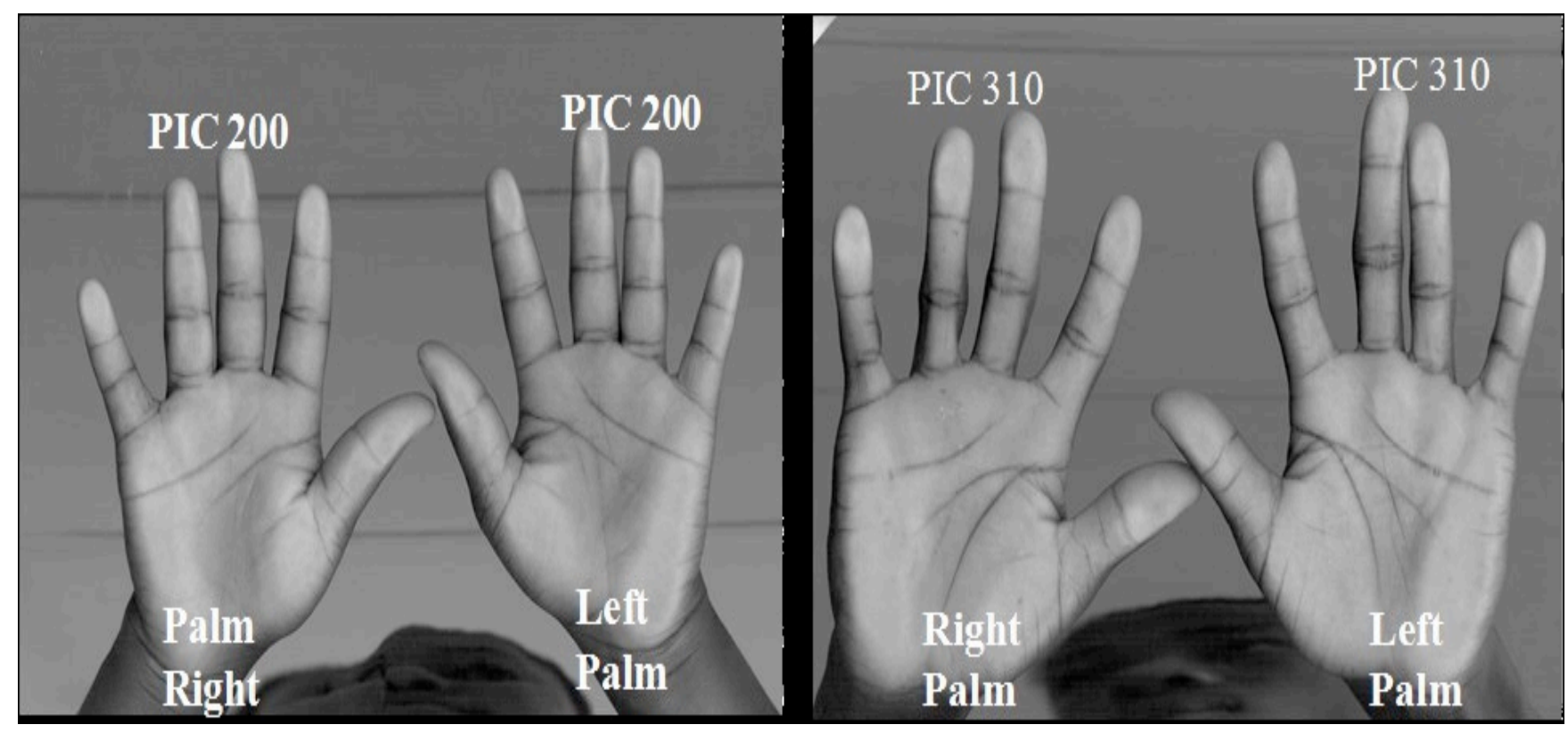

Figure 1: PIC patterns of palm print in the above two subjects. (Note that one subject shows PIC 200 in the right palm and left palm. The other subject shows PIC 310 in the right palm and left palm) Offei et al., 2014.

\begin{tabular}{|cccc|}
\hline $\begin{array}{l}\text { PIC Criteria } \\
\text { line }\end{array}$ & No of Creases & Intersection & Transverse \\
\hline 300 & 3 & None & None \\
310 & 3 & One & None \\
200 & 2 & None & None \\
& & & \\
\hline
\end{tabular}

\section{RESULTS}

The study revealed that in the palmar flexion creases of 300 subjects whose 600 palms were studied, percentage of PIC 300 bilaterally was greater in the hands of multiple births women $(52.4 \%)$ than single births women $(37.4 \%)$ of Igbo-Ora indigenes and the difference was 
statistically significant $p<0.005$ while in multiple births women of Ogbomosho PIC 300 was also higher $(54.0 \%)$ than single births women $(37.0 \%)$ but was not statistically significant, $p>0.005$.
In Single birth women of both Igbo-Ora and Ogbomosho, PIC 310 bilaterally was found to be higher in both hands compared to multiple births women of Igbo-Ora and Ogbomosho, and the difference was statistically significant $\mathrm{p}<$ 0.005 .

Table 1.0: Palmar flexion creases (PIC Criteria between multiple and single births women of Igbo-Ora) Group I and II.

\begin{tabular}{|l|l|l|l|l|l|l|l|l|}
\hline PIC/FREQ & $300(\%)$ & $310(\%)$ & $320(\%)$ & $211(\%)$ & $210(\%)$ & $201(\%)$ & $200(\%)$ & TOTAL \\
\hline $\begin{array}{l}\text { Multiple } \\
\text { Birth (both } \\
\text { hands) }\end{array}$ & $110(52.4)$ & $86(41.0)$ & $1(0.5)$ & $0(0.0)$ & $5(2.3)$ & $1(0.5)$ & $7(3.3)$ & 210 \\
\hline $\begin{array}{l}\text { Single Birth } \\
\text { both hands) }\end{array}$ & $71(37.4)$ & $110(57.9)$ & $0(0.0)$ & $1(0.5)$ & $4(2.1)$ & $0(0.0)$ & $4(2.1)$ & 190 \\
\hline $\begin{array}{l}\text { Chi-square } \\
\text { P-value }\end{array}$ & 9.934 & 10.593 & 0.920 & 1.092 & 0.864 & 0.920 & 0.599 & \\
\hline
\end{tabular}

Table 2.0: Palmar Flexion Creases among multiple and single births women of Ogbomosho Group III and IV.

$\begin{array}{lcccccccc}\begin{array}{l}\text { PIC/FREQ } \\ \text { Multiple Births } \\ \text { (both hands) }\end{array} & 300(\%) & 310(\%) & 320(\%) & 211(\%) & 210(\%) & 201(\%) & 200(\%) & \text { TO'TA } \\ \begin{array}{l}\text { Single Births } \\ \text { (both hands) }\end{array} & 38(34.0) & 44(44.0) & 0(0.0) & 0(0.0) & 1(1.0) & 0(0.0) & 1(1.0) & 100 \\ \begin{array}{l}\text { Chi-square } \\ \text { P-value }\end{array} & 2.763 & 1.922 & 0.000 & 0.000 & 0.000 & 0.000 & 1.800 & \\ \end{array}$

Table 3.0: Comparison of Palmar Flexion Creases among women of Igbo-ora and Ogbomosho.

\begin{tabular}{|c|c|c|c|c|}
\hline \multirow[t]{2}{*}{ PIC/FREQ } & \multicolumn{2}{|c|}{ Multiple Births } & \multicolumn{2}{|c|}{ Single Births } \\
\hline & $\begin{array}{l}\text { Igbo-Ora } \\
\text { Freq (\%) }\end{array}$ & $\begin{array}{l}\text { Ogbomosho } \\
\text { Freq (\%) }\end{array}$ & $\begin{array}{l}\text { Igbo-Ora } \\
\text { Freq (\%) }\end{array}$ & $\begin{array}{l}\text { Ogbomosho } \\
\text { Freq (\%) }\end{array}$ \\
\hline 300 & $110(52.4)$ & $54(54.0)$ & $71(37.4)$ & $38(38.0)$ \\
\hline 310 & $86(41.0)$ & $44(44.0)$ & $110(57.9)$ & $58(58.0)$ \\
\hline 320 & $1(0.5)$ & $0(0.0)$ & $0(0.0)$ & $0(0)$ \\
\hline 211 & $0(0)$ & $0(0)$ & $1(0.5)$ & $0(0)$ \\
\hline 210 & $5(2.3)$ & $1(1.0)$ & $4(2.1)$ & $0(0)$ \\
\hline 201 & $1(0.5)$ & $0(0)$ & $0(0)$ & $0(0)$ \\
\hline 200 & $1(1.0)$ & $1(1.0)$ & $4(2.1)$ & $4(0)$ \\
\hline Total & $210(100)$ & $100(100)$ & $190(100)$ & $100(100)$ \\
\hline
\end{tabular}


Anatomy Journal of Africa. 2020. Vol 9 (1): 1744 - 1751.

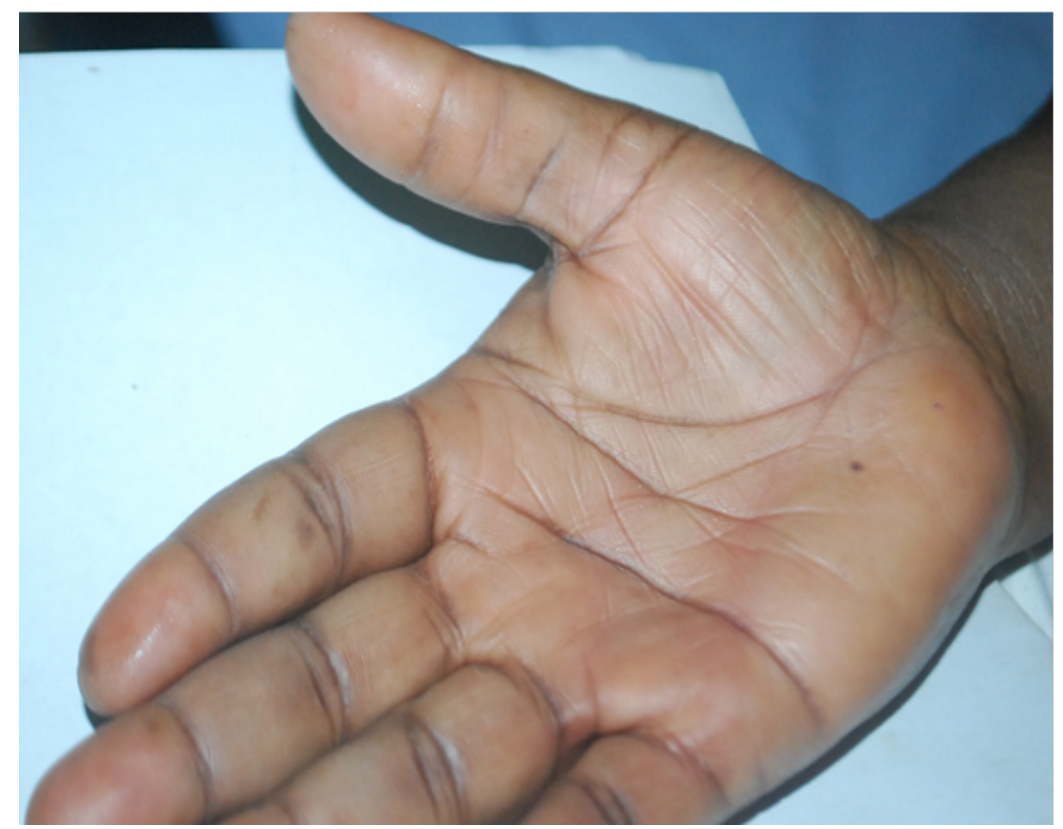

Figure 2: Right hand of the woman showing three palmar lines with intersection
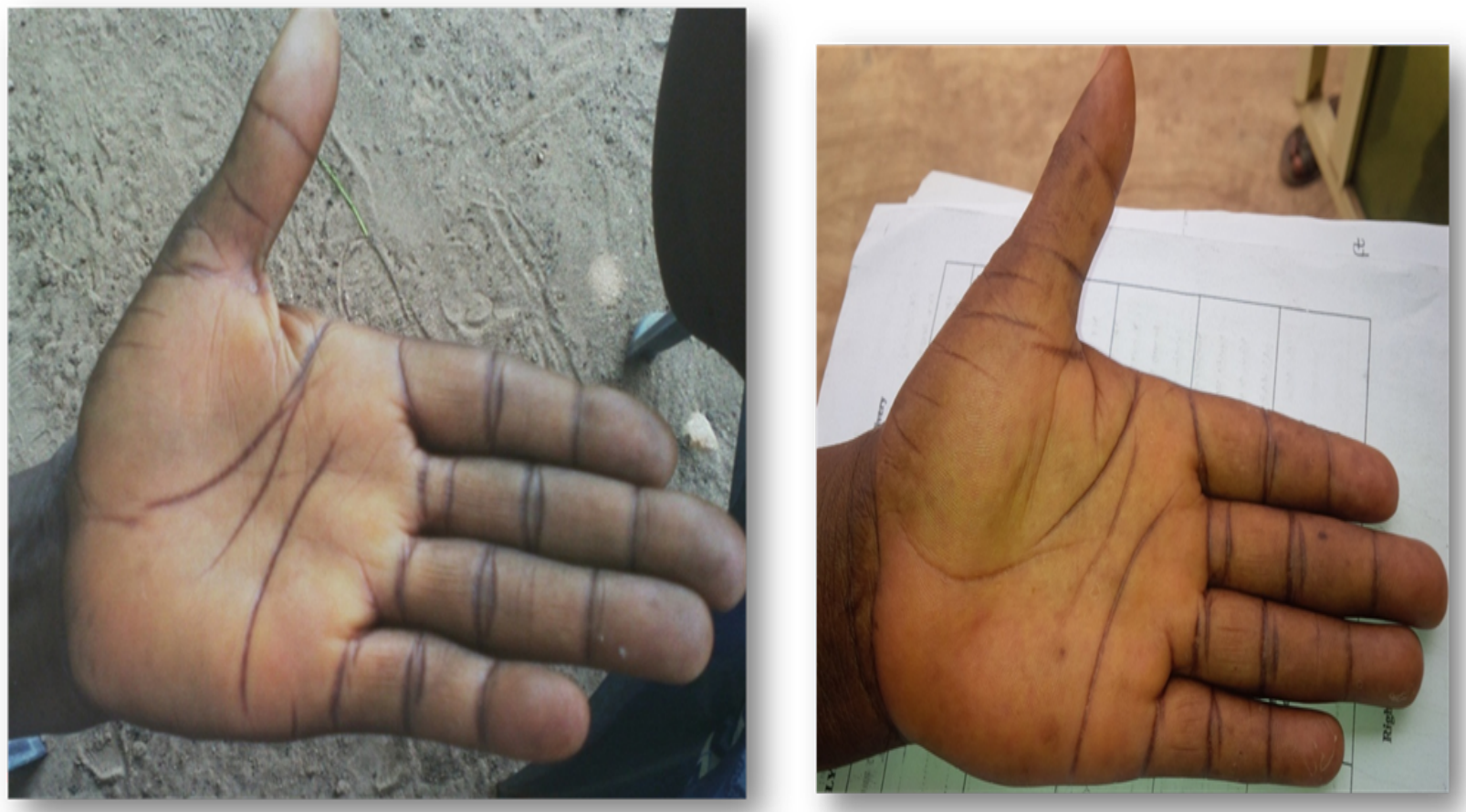

Figure 3: Picture of the left hand of two women showing different PIC criteria

\section{DISCUSSION}

Dermatoglyphics is also known to be one of the best available diagnostic tools in genetic disorders especially diseases with obscure etiology and mysterious pathogenesis such as down syndrome, celiac disease, low birth weight, congenital deafness, cancer and 
leukemia (Karthick et al., 2015; Afework, 2019). Patterns of epidermal ridges have a role in diagnosing and delineating certain syndromes of congenital malformation (Bhardwaj et al., 2015). Palmar creases have been closely related to numeral aberration of chromosomes (Chung et al., 2000). Occurrence of abnormal palmar creases in seemingly normal individuals have also been reported in other studies (Sharma and Sharma, 2010; Taura et al., 2014; Afework, 2019).

In all the biometrics studied, palm has an advantage over other biometrics like face, voice and fingerprint in that it has large number of features that can be used as biometric features (Kumar et al., 2003). Also, palm is less prone to injury, and its usefulness in predicting academic performance (Offei et al., 2014) also made us to assess its relationship to multiple births. In this study, it was found that the percentage of PIC 300 in both hands of Igbo-Ora and Ogbomosho multiple births women were greater than single births women $\mathrm{p}<0.005$, while PIC 310 in both hands of the Igbo-Ora and Ogbomosho women were also greater in single births women than multiple births women which is in agreement with study done by Rosa et al., 2001 which found normal palmar lines in stronger children and (Alhaji et al., 2015) observed the same palmar lines as predominant

Conflict of Interest: The authors declared that there is no conflict of interest in the publication of this manuscript.

Limitation of the study: Fund to procure a hand scanner instead of using stamp pad ink and lack of prior research

on this topic.

Delimitation: The study was conducted on South-West geo-political zone of the country, therefore to generalize the result for a larger group; the study should have involved more geo-political zones of the country

\section{REFERENCES}

1. Achebe C. 1994. Things fall apart. New York, Anchor Books pg. 125

2. Afework M. 2019. Prevalence of the different types of palmar creases among medical and dental students in Addis Ababa, Ethiopia. Ethiop J Health Sci.; 29(3):391-400. doi: 10.4314/ejhs. v29i3.12

3. Akinboro A, Azeez MA, Bakare AA. 2008. Frequency of twinning in Southwest Nigeria. Indian J Hum Genet.14 (2):41-47. in seemingly normal Hausa ethnic population . Another closely related study carried out in and Fawehinmi, 2009 also supported the single birth women findings which showed intersected palmar flexion crease to be higher in the weaker women than the stronger women.

In this study, it was observed that Igbo-Ora and Ogbomosho multiple births women had 300 ), compared to the single birth women of Igbo-Ora and Ogbomosho who had an intersection in their three palmar flexion creases (PIC310) which implies that multiple births women had three unintersected primary palmar creases and are stronger.

This study has shown that women with three unintersected palmar flexion creases are more likely to give birth to multiples than women with an intersection of the three palmar flexion creases whose chances of given birth to

In conclusion, based on this study, one can clearly say that there is a relationship between a woman's tendency of giving birth to multiples and dermatoglyphics (which is a simple noninvasive, inexpensive anatomical marker). 
4. Alhaji MM, Timbuak J, Umana UE, Tanko M. 2015. Palmar creases and handedness in hausa of Northern Nigeria: A cross-sectional study. AJBMS, 1 (2):6-13.

5. Bastian ML. 2001. "The Demon Superstition" Abominable twins and mission culture in Onitsha (1), Ethnology, 40(1):13

6. Bhardwaj N, Bhardwaj P, Tewari V, Siddiqui MS. 2015. Dermatoglyphic analysis of fingertip and palmer print patterns of obese children. Int J Med Sci Public Health 4: 946-949

7. Chung MS, Kim YS, Kim HJ, Sohn HJ, Han HS. 2000. Dermatoglyphic characteristics of the Korean patients with numerical aberrations of chromosome. Korean J Phys Anthropol, 13, 3138.

8. Cummins H Midlo C. 1961. Fingerprints palm and soles- Introduction to dermatoglyphics. Dover Publication Inc. New York.

9. Dehankar RN, Ksheersagar DD. 2012. Study of palmar dermatoglyphics in twins. Pak J Med Sci, 2(1);17-20.

10. Eboh D, Arko-Boham B. 2008. Genetics and fingerprint: J Anthropol, 2012: 10-16.

11. Ghosh JR, Ghosh DP, Dey B, Bandyopadhyay AR. 2016. Finger and palmar ridge pattern in NIDDM patients and controls. Hum Biol Rev, 5 (1); 86-91. Biometric Person Authentication (AVBPA). pp. 668-678.

12. Karthick MK, Babu NA, Krupaa RJ, Anitha N. 2015. Dermatoglyphics: A review. Biomed Pharmacol J, 8 (Oct Spl). Available from: http://biomedpharmajournal.org/?p=3748.

13. Kulkami AD, Jamieson DJ, Jones HW, Kissim DM, Gallo MF, Macaluso MA, Jones HW, Kissin D, M, Gallo MF, Macaluso M, Adashi EY. 2013. Fertility treatments and multiple births in the United States. N Engl J Med, 369 (23):2218-2225. PMID 24304051. doi:10.1056/NEJMoa1301467

14. Kumar AD, Wong CM, Shen HC, Jain AK. 2003. Personal verification using palmprint and hand geometry biometric. In Proc. 4th Internat. Conf. On Audio- and Video-Based

15. Lazarov S, Lazarov L, Lazarov N. 2016. Complications of multiple pregnancy: Overview. Rakia J Sc, $1 ; 108-111$.

16. Mosuro AA. 1996. Twinning rates in South West Nigeria. Nigeria Journal of Science, 30: 39-45

17. Offei EB, Abledu JK, Osabutey CK, Kesse DK. 2014. Relationship between palmar dermatoglyphic pattern and academic performance of students in a Ghanaian secondary school. J Med Biomed Sc, 3 (2): 24-31.

18. Oladipo GS, Eberechi D, Okoh PD. 2012. Comparative study of digital pattern position of triradius b-c and a-d palmar distances of diabetic subjects and essential hypertensive individuals in Rivers State. Int J Adv Biotechnol Res, 3 (2): 615-620

19. Oyinbo CA, Fawehinmi HB. 2009. Prevalence of Simian and Sydney creases in the Ijaws of South- South Nigeria. Int J Bio Anthropol, 3(2):https://ispub.com/IJBA/3/2/9763

20. Ravindranath R, Thomas IM. 1995. Finger ridge count and finger print pattern in maturity onset diabetes mellitus. Ind J Med Sci. 49 (7):153-156

21. Rosa A, Gutierez B, Guerra A, Arias B, Fananas I. 2001. Dermatoglyphics and abnormal palmer flexion creases as markers of early prenatal stress in children with idiopathic intellectual disability. JIDR, 45 (2):416-423

22. Sharma DK, Sharma V. 2010. Prevalence of Simian, Sydney and Suwon creases and their association with each other, body sides, handedness, gender and anomalies/diseases/syndromes in a population of central India. Int J Morphol, 29 (3), 10691075.

23. Smits J, Monden C. 2011. Twinning across the developing world. PLoS One, 6 (9):1-4.

24. Taura AA, Taura MG, Adamu LH. 2014. Palmar Creases; A comparative study between epilepsy patients and healthy subjects among hausas of Northern Nigeria. Am J Med Med Sci, 4 (5), 175-179. 
Anatomy Journal of Africa. 2020. Vol 9 (1): 1744 - 1751.

25. Wu X, Zhang D, Wang K, Huang B. 2004. Palmprint classification using principal lines. Pattern recognit, 37: 1987-1998.

26. Yamane T. 1967. Statistics. An Introduction, Analysis, $2^{\text {nd }}$ Ed. New York, Harper and Row. 